\title{
Analysis on 'Role' Transformation of English Teachers in Chinese Higher Vocational Colleges from Traditional Classroom to Flipped Classroom under SMCR Model
}

\author{
Ziqi $\mathrm{Li}^{1 *}$ \\ ${ }^{1}$ Monash University, Clayton Campus, Wellington Road, Victoria 3800, Australia
${ }^{*}$ Corresponding author. Email: 958340985@qq.com
}

ABSTRACT

The emergence of flipped classroom has made a huge impact on traditional teaching model in China, transforming the classroom from teacher-directed to students-directed. It is particularly important to introduce English flipped classroom into Chinese higher vocational colleges and explore the English teaching model with the characteristic of higher vocational education. This study indicates the current situation of English teaching in Chinese higher vocational colleges. From the perspective of SMCR model, it aims to explore problems faced by English teachers in 'role' transformation from traditional classroom to flipped classroom, propose how they should transform their roles to improve the teaching quality, and discuss this impact on traditional English classroom. It points that with popularization of English flipped classroom in Chinese higher vocational colleges, both students and teachers can achieve the best teaching effect.

Keywords: Chinese higher vocational colleges, English flipped classroom, traditional English classroom, English teachers, 'role' transformation, SMCR model

\section{INTRODUCTION}

With the innovation of educational concept and the rapid development of network technology, flipped classroom, as a new educational way for students to learn, has become a hot spot in current education. It refers to the process by which students learn new knowledge is put outside of the classroom and can be done by watching videos and other media, and class time is used to discuss and answer questions encountered during study [1] [2] [3]. In Chinese higher vocational colleges, the application of flipped classroom completely overturns the traditional classroom, and with the characteristic of its new teaching model, it has improved the quality of English teaching.

In 1960, D.K. Berlo proposed the SMCR model (see Figure 1 [4]), who summarized the communication process into four elements: source, message, channel and receiver. From the perspective of Berlo's SMCR model, in English flipped classroom of Chinese higher vocational colleges, teachers are sources, students are receivers, message is the teaching content and teaching method that possessed by teachers as optimal material to achieve the ideal teaching effect. In order to accurately transfer message from the source to the receiver, certain teaching tools also play an important point during this process, in other words, the choice of channel will affect the realization of teaching effect [2]. Therefore, using this model can clearly analyze how English teachers in Chinese higher vocational colleges transform the 'role' from traditional classroom to flipped classroom.

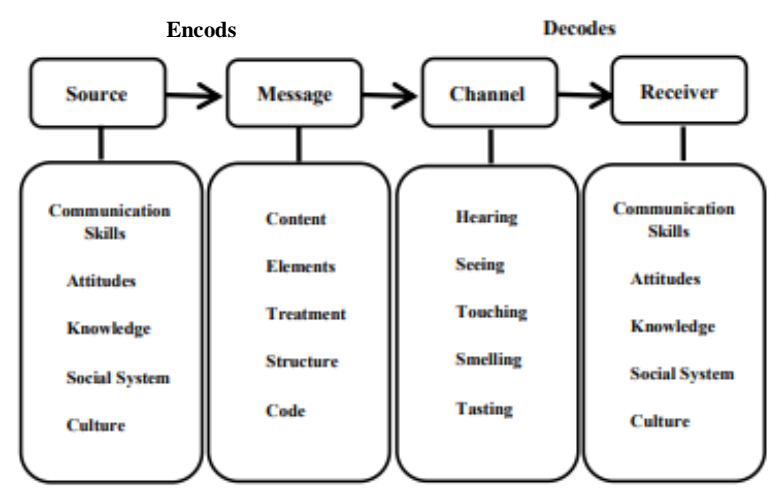

Figure 1 Berlo's SMCR Model [4] 


\section{THE CURRENT SITUATION OF ENGLISH TEACHING IN CHINESE HIGHER VOCATIONAL COLLEGES}

\subsection{Mainly Taught by Traditional English Classroom and Supplemented by English Flipped Classroom}

Under traditional classroom, the teacher is a leader who stands in front of stage teaching all lessons throughout the whole class, while students are audiences during this period [5]. The defect is that there is too much book knowledge, too little practice training, too many common standards, too little personal interests [6]. Flipped classroom, through the use of online video lessons, can be learned anywhere, anytime. It facilitates learning resource sharing and enhances students' learning interest, making the class filled with vigor.

In Chinese current higher vocational education, the class is based on traditional teaching model and supplemented by flipped classroom. In terms of English flipped classroom, it has completely satisfied individual needs and made students learn language in an efficient and pleasant atmosphere. Students can watch online videos repeatedly, teachers can save the time of repeating lessons in class as well, so that traditional classroom can be used for discussing learning problems. Therefore, with the combination of these two teaching models in higher vocational colleges, it is quite suitable for both instilled learning of traditional classroom and autonomous learning of flipped classroom.

\subsection{Exam-Oriented English Teaching Environment}

In China, students in higher vocational colleges are required to reach the national English proficiency level A or B in PRETCO exam (national practical English test in China for higher vocational colleges students), and colleges take the pass rate as an important index to measure the teaching quality of teachers [7]. For this reason, teachers rely on book knowledge more and cannot innovate the teaching content. Students may regard English as a subject, a test rather than a language to learn. With the emergence of flipped classroom, examoriented English teaching environment in Chinese higher vocational education has improved a lot. Students can enhance their intercultural ability and gradually see English as a bridge to connect with the world, rather than a test. Teachers need to realize that, it is vital to explore English teaching model with the characteristic of higher vocational education, that is, guiding students to become high compound applied talents so as to adapt to the needs of economic globalization.

\section{PROBLEMS OF 'ROLE' TRANSFORMATION OF TEACHERS IN ENGLISH FLIPPED CLASSROOM}

\subsection{Teacher Issues}

Flipped classroom is difficult in curriculum arrangement, and teachers are the key to it. In SMCR model, the source contains several factors: communication skills, attitudes, knowledge, social system and culture. English teachers in Chinese higher vocational colleges, as the source in communication process, can be roughly divided into two groups: young teachers and middle-aged teachers, who have different levels of knowledge, educational background, prestige and etc, facing various dilemmas in flipped classroom. Middle-aged teachers with abundant teaching experience prefer to traditional classroom, as it is difficult for them to skillfully use too much network technology. In flipped classroom, teachers should not only master basic computer skills, but also learn to record teaching videos, communicate online and track feedback, which is a great test for middle-aged teachers. For young teachers, although they are skilled in computer technology, their lack of teaching experience couldn't achieve the optimization and maximization of teaching effect.

Therefore, in English flipped classroom in Chinese higher vocational colleges, from the course design to the follow-up communication with students in the later stage, teachers need to constantly improve their teaching skills, so that which can motivate students' learning interests and enhance their autonomous learning ability. In this way, teaching effect of flipped classroom can be achieved as well.

\subsection{Students Issues}

According to SMCR model, receiver is not only the one who receives the message and decodes it, but also the one who sends the feedback to the source [2]. For effective communication, it means that the receiver needs to understand the meaning of message [4]. During this process, students, as receivers, their learning performance is also affected by their communication skills, attitudes, knowledge, social system and culture. In China, most students in higher vocational colleges are not active in learning, and the traditional English teaching model makes them too dependent on 'cramming' teaching and unable to explore and study independently. The proposal of flipped classroom has undoubtedly overturned this teaching model. However, in flipped classroom, the biggest difficulty is still that students do not actively cooperate, especially the students who lack of learning attitude, which makes it difficult to achieve the teaching purpose of flipped classroom. Besides, due to limited knowledge level, higher vocational colleges students will meet obstacles in completing learning tasks 
independently. Many students think that it is a burden for them to preview lessons.

As the above issues, we need to realize that students are the main body of study, if they are in a passive learning state, it is hard for them to get benefits from flipped classroom. Thus, in the process of turning, only when students' learning and teachers' guidance cooperate with each other can show the significant effect of flipped classroom.

\section{The PATH OF 'ROLE' TRANSFORMATION OF TEACHERS IN ENGLISH FLIPPED CLASSROOM}

In SMCR model, teachers, as the source of message, are the key to flipped classroom. They need to improve their professional abilities to achieve a full range of 'role' changes in flipped classroom, which is a challenge for teachers. In view of the problems that English teachers in Chinese higher vocational colleges face in the transition from traditional classroom to flipped classroom, how to transform the 'role' can be analyzed from the following aspects.

\subsection{Become a Learner of English Flipped Classroom}

In an English flipped classroom, the teacher's first role should be the learner. It is required that teachers must master the information technology ability to make teaching videos, in other words, both young and middleaged teachers need to adapt to this new trend and constantly improve their teaching effect. For instance, young teachers are skilled in using new media, but lack of teaching experience; middle-aged teachers have rich teaching experience, but lack of multimedia technology. As the two main teaching forces in Chinese higher vocational colleges, they shall learn from each other. Young teachers can consult old teachers for teaching methods and improve their teaching level. Middle-aged teachers, who may have not much contact with computer technology in their youth and lack of further connection and communication with the information age, can consult young teachers about how to use multimedia applications to make flipped classroom more vividly and keep it with the times. Only when teachers constantly improve themselves and learn from each other can further achieve the teaching purpose of English flipped classroom.

\subsection{Become a Designer of English Flipped Classroom}

The teacher is the organizer and designer of the classroom. Whether in traditional classroom or flipped classroom, the teacher must design teaching activities effectively. Based on flipped classroom, the role of the designer needs to be further strengthened. When preparing teaching resources and recording videos, English teachers in Chinese higher vocational colleges should carefully design courseware this is suitable for students to watch and master.

Higher vocational colleges students lack initiative in learning, which needs teachers to increase the interest of teaching videos and courseware design as well, so as to stimulate the enthusiasm of students in English learning. For example, in spoken English flipped classroom, teachers can arrange learning tasks such as video dubbing to create a pleasant learning atmosphere. With the combination of network technology and flipped classroom, it gives students a unique learning experience. If the teacher plays a good role as the designer of teaching activities, makes full use of the channel in SMCR model, the student's learning effect will be continuously improved.

\subsection{Become an Introspector of English Flipped Classroom}

Different from traditional classroom, flipped classroom is an autonomous learning way based on students' own needs and arrangements, and teachers are required to instruct students offline. In English flipped classroom of Chinese higher vocational colleges, through receiving feedback from class and interacting with students offline, teachers can clearly know about students' mastery degree, reflect their own teaching method and play the role of designer better.

From these roles of teachers in English flipped classroom, we can conclude that they are interlinked. In order to better achieve the teaching purpose of flipped classroom, teachers need to make a good conversion of them during teaching process.

\section{THE IMPACT OF 'ROLE' TRANSFORMATION OF TEACHERS IN ENGLISH FLIPPED CLASSROOM on TRADITIONAL ENGLISH CLASSROOM}

\subsection{Interaction Between Teachers and Students}

Compared with traditional English classroom, flipped classroom helps to develop students' independent learning ability. The essence of the implementation process of flipped classroom is to reverse 'knowledge transfer' and 'knowledge internalization' process of the traditional teaching model [8], so that students in Chinese higher vocational colleges will no longer play a passive role in English learning. In addition, with abundant online English learning resources, students can also broaden their horizons and improve the ability of intercultural communication [3]. 
For teachers, in English flipped classroom, students have already internalized what they have learned, and teachers can give specific guidance and help offline according to students' learning situation [1]. Besides, from traditional classroom to flipped classroom, teachers need to learn the new teaching way and improve the level of information technology. In the context of Chinese culture, how to localize this new teaching model needs the teacher to be local explorer, watchman and integrator during teaching [9].

\subsection{The Change of English Teaching Concept}

Previously, Chinese higher educational field preferred traditional English classroom more as teachers and students could communicate with each other face-toface, but with the emergence of COVID-19 epidemic in 2020, it seemed too difficult for students to learn in such traditional way. As a new teaching model, English flipped classroom has a great impact on traditional classroom in higher vocational colleges. It can break the limitation of time and space, and with support of big data, students can learn in an efficient and intelligent environment. Under this condition, this new teaching way is gradually accepted and praised by the crowd.

\section{CONCLUSION}

Combining SMCR model with flipped classroom in Chinese higher vocational colleges can better interpret the 'role' transformation of English teachers under this new teaching model. Flipping process is not simply the subversive change of knowledge transfer and knowledge internalization process, but in essence, the change of teaching place, the change of the role of the leader and participants, the change of the preset and generation of teaching content [10]. In English flipped classroom of Chinese higher vocational colleges, teachers need to transform the 'role' from traditional classroom to flipped classroom, and students should also change from passive learners to active learners. Only by adapting to this new teaching model can flipped classroom achieve the best teaching effect.

\section{AUTHORS' CONTRIBUTIONS} paper.

$\mathrm{Zi}$. Li conceived the idea of this study and wrote the

\section{ACKNOWLEDGMENTS}

I would like to send my sincere gratitude to Miss Yue Pan from Tianjin University of Technology and Education, Miss Yi He from University of New South Wales, Miss YunYan Geng from Tianjin Normal University for all their kind help and guidance on this paper.

\section{REFERENCES}

[1] J. Strayer, How Learning in an Inverted Classroom Influences Cooperation, Innovation and Task Orientation, no. 15, Learning Environments Research, 2012, pp. 171-193. DOI: 10.1007/s10984-012-9108-4

[2] Xu. Dong and Wen. Hu, Analysis on 'Flipped Classroom' Teaching Model from the Perspective of SMCR Communication Model, no. 1, Primary and Middle School Educational Technology, 2013, pp. 26-28.

[3] Xiao. Li and Hong. Cao, Research on Flipped Teaching Model on the Basis of Micro-Lecture ---taking College English Film and Television Class as an Example, vol. 25, no. 9, Modern Educational Technology, 2015, pp. 70-76.

[4] Berlo's SMCR Model of Communication, Retrieved from http://www.communicationtheory.org/berlos-smcrmodel-of-communication/

[5] Rui. Chen, A Hybrid English Teaching Model Based on Traditional Classroom and Flipped Classroom in Higher Vocational Colleges, vol. 1, no. 3, Hebei Vocational Education, 2017, pp. 64-66, pp. 75.

[6] Lan. Luan, Research on Flipped Classroom Model of Higher Vocational English Education from the Perspective of MOOC, no. 2, Teaching of Forestry Region, 2020, pp. 50-52.

[7] He. Kong, A Hybrid English Teaching Model Based on Traditional Classroom and Flipped Classroom in Higher Vocational Colleges, vol. 3, no. 36, Comparative Study of Cultural Innovation, 2019, pp. 121-122.

[8] Xin. Ma, The Influence of Flipped Classroom on College English Teaching, Jilin Daily, 2015, pp. 1-2.

[9] Bo.Ye, Beyond Technology: The Role of Teachers in Flipped Classroom Implementation, no. 8, Journal of the Chinese Society of Education, 2015, pp. 82-85.

[10] Xiao. Wang, Li. Su and Feng. Dong, Improve the Self-Learning Ability of English Teachers in Flipped Classroom in Higher Vocational Colleges, no. 5, Knowledge World, 2015, pp. 1. 